TITLE:

\title{
Investigation of Electrochemical Sodium-Ion Intercalation Behavior into Graphite-Based Electrodes
}

\section{$\operatorname{AUTHOR}(S)$ :}

Kondo, Yasuyuki; Fukutsuka, Tomokazu; Miyazaki, Kohei; Miyahara, Yuto; Abe, Takeshi

\section{CITATION:}

Kondo, Yasuyuki ... [et al]. Investigation of Electrochemical Sodium-Ion Intercalation Behavior into Graphite-Based Electrodes. Journal of The Electrochemical Society 2019, 166(3): A5323-A5327

\section{ISSUE DATE:}

2019

URL:

http://hdl.handle.net/2433/237835

\section{RIGHT:}

(c) The Author(s) 2019. Published by ECS. This is an open access article distributed under the terms of the Creative Commons Attribution Non-Commercial No Derivatives 4.0 License (CC BY-NC-ND,

http://creativecommons.org/licenses/by-nc-nd/4.0//, which permits non-commercial reuse, distribution, and reproduction in any medium, provided the original work is not changed in any way and is properly cited. For permission for commercial reuse, please email: oa@electrochem.org. 
JeS Focus Issue of Selected PAPers from IMLB 2018

\title{
Investigation of Electrochemical Sodium-Ion Intercalation Behavior into Graphite-Based Electrodes
}

\author{
Yasuyuki Kondo, ${ }^{1}$ Tomokazu Fukutsuka, ${ }^{1,2, *}$ Kohei Miyazaki, ${ }^{1,2,3, *}$ Yuto Miyahara, ${ }^{1}$ \\ and Takeshi Abe $\mathbb{1}^{1,2,3, *, z}$ \\ ${ }^{I}$ Graduate School of Engineering, Kyoto University, Nishikyo-ku, Kyoto 615-8510, Japan \\ ${ }^{2}$ Hall of Global Environmental Research, Kyoto University, Nishikyo-ku, Kyoto 615-8510, Japan \\ ${ }^{3}$ Element Strategy Initiative for Catalysts \& Batteries (ESICB), Kyoto University, Nishikyo-ku, Kyoto 615-8246, Japan
}

\begin{abstract}
Sodium-ion batteries cannot employ graphite which is a typical negative electrode material for lithium-ion batteries. This is principally because sodium-ion cannot intercalate deeply into graphite, which has been a mystery for many years. Here, the mechanism of electrochemical sodium-ion intercalation into graphitic materials was investigated by using Raman spectroscopy and X-ray diffraction measurement to solve the question. Low stage sodium graphite intercalation compound (Na-GIC) was formed electrochemically only near the surface of graphite by potential holding above the sodium metal deposition potential. On the other hand, the high stage NaGIC was formed electrochemically in the bulk at the sodium metal deposition potential. In addition, the apparent diffusion distance and the apparent diffusion coefficient of sodium-ion inside graphite were calculated using chronopotentiograms and potentiostatic intermittent titration technique. As a result, the sodium-ion diffusion inside spherical graphite was not slow enough to explain the limited reactivity. Hence, the limitation of sodium-ion intercalation into graphite might be originated from not the kinetic limitation inside graphite but the thermodynamic limitation.

(C) The Author(s) 2019. Published by ECS. This is an open access article distributed under the terms of the Creative Commons Attribution Non-Commercial No Derivatives 4.0 License (CC BY-NC-ND, http://creativecommons.org/licenses/by-nc-nd/4.0/), which permits non-commercial reuse, distribution, and reproduction in any medium, provided the original work is not changed in any way and is properly cited. For permission for commercial reuse, please email: oa @ electrochem.org. [DOI: 10.1149/2.0431903jes]
\end{abstract}

(cc) BY-NC-ND

Manuscript submitted October 29, 2018; revised manuscript received December 11, 2018. Published January 12, 2019. This paper is part of the JES Focus Issue of Selected Papers from IMLB 2018.

Lithium-ion batteries (LIBs) have been mainly used in the field of portable devices. Recently, large-scale applications of LIBs such as plug-in hybrid electric vehicles (HEV), electric vehicles (EV) and stationary power storages have attracted much attention principally due to the reduction of carbon dioxide. For these applications, vast lithium must be consumed, resulting in the future shortage of lithium sources. ${ }^{1}$ This expectation and the abundant sodium sources are behind the vast studies on sodium-ion batteries (SIBs).

Sodium-ion batteries can be fabricated by a similar manner of LIBs using sodium containing transition oxides, carbonaceous materials, and sodium-ion conducting organic electrolyte solutions as positive, negative electrodes, and electrolyte, respectively. ${ }^{2}$ Carbonaceous materials for the negative electrode in SIBs are slightly different from those in LIBs. It is quite well-known that graphite has been mainly used for LIBs since the graphite shows the potential as low as lithium metal, high capacity of $372 \mathrm{mAh} / \mathrm{g}$ in addition to the cost. Non-graphitizable carbon, so called hard carbon, has been also used as a negative electrode of LIBs for high power use. In contrast, hard carbons are mainly used in SIBs and the reversible capacity was reported to be about $200 \mathrm{~mA} \mathrm{~h} \mathrm{~g}^{-1} \cdot 1,3,4$ This is because the sodium-ion intercalation/deintercalation capacity of graphite was negligibly small. ${ }^{2}$ If sodium-ion can be sufficiently intercalated into graphite, low cost and high volumetric energy density of SIBs can be fabricated.

As mentioned above, sodium-ion hardly intercalates into graphite electrode. Less reactivity of sodium with graphite has been known for many years. Reaction of intercalated species and graphite leads to graphite intercalation compounds (GICs), and the GICs can be prepared by various methods such as vapor method, chemical (electrochemical) solution method, etc. ${ }^{5}$ Alkali metal-GICs except for sodium can show stage $1 .{ }^{5}$ Here, a stage is defined by the number of graphene layers between the intercalated layers.

Preparation of Na-GICs has been conducted for many years. ${ }^{6-8}$ Asher et al. firstly performed the synthesis of stage 8 Na-GIC. ${ }^{6}$ After

*Electrochemical Society Member.

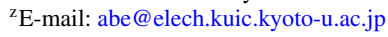

that, Herold et al. succeeded the preparation of stage 6 and stage 7 Na-GICs. ${ }^{7}$ Low stage Na-GICs have been prepared only by the synthesis under high pressure condition. ${ }^{9}$ In addition, only high stage Na-GICs were reported by an electrochemical method, and low stage Na-GICs has not been obtained. ${ }^{10,11}$

Probable reasons for the less reactivity of sodium and graphite are 1) in-commensurate in-plane structure, 2) small diffusion coefficient. Stage $1 \mathrm{Li}-\mathrm{GIC}$ corresponds to $\mathrm{LiC}_{6}$ whose in-plane structure can be denoted by $\mathrm{p}(\sqrt{ } 3 \times \sqrt{ } 3) \mathrm{R} 30^{\circ}$. For stage $1 \mathrm{~K}-$-, Rb- and Cs-GIC, $\mathrm{p}(2 \times 2) \mathrm{R} 0^{\circ}$ in-plane structure is formed. If these two in-plane structures form in Na-GICs, the large distortion of graphite networks may occur by considering the ionic radii of sodium-ion. As a result, formation of low stage Na-GICs is unfavorable, which was also confirmed by the calculation of formation energies of alkali metal-GICs. ${ }^{12}$ This explanation may be rational, but some GICs show the in-commensurate in plane structures.

Slow diffusion of sodium-ion though the graphene layers may account for only high stage Na-GIC formation. Diffusion coefficient of sodium-ion inside graphitic materials over $700^{\circ} \mathrm{C}$ was around $10^{-5} \mathrm{~cm}^{2} \mathrm{~s}^{-1}$ and it was not so slow as compared to that of lithium ion. ${ }^{13}$ Then, it will be interesting to evaluate the sodium-ion diffusion rate at room temperature since the value is still uncertain.

The mechanism of electrochemical sodium-ion insertion into graphitic materials was also discussed by using a petroleum coke, which is one of the graphitizable carbons. ${ }^{14,15}$ Larger reversible capacities of sodium-ion insertion into the petroleum cokes were observed after grinding ${ }^{14}$ or thermal treatment at low temperature, ${ }^{15}$ suggesting that lower crystallized carbons should show higher reactivity with sodium ion. The correlation between the carbon crystallinity and the reactivity of sodium-ion may be interesting, but the details are remained unclear.

Here, we investigated both thermodynamic and kinetic properties of electrochemical sodium-ion intercalation into graphite to understand the limited reactivity of sodium-ion and graphite. In particular, we shed light on the electrochemical reaction on the surface as well as that at the bulk of graphitic materials. To evaluate the apparent diffusion coefficients of sodium-ion inside graphite, potentiostatic intermittent titration technique (PITT) ${ }^{16}$ was performed. 


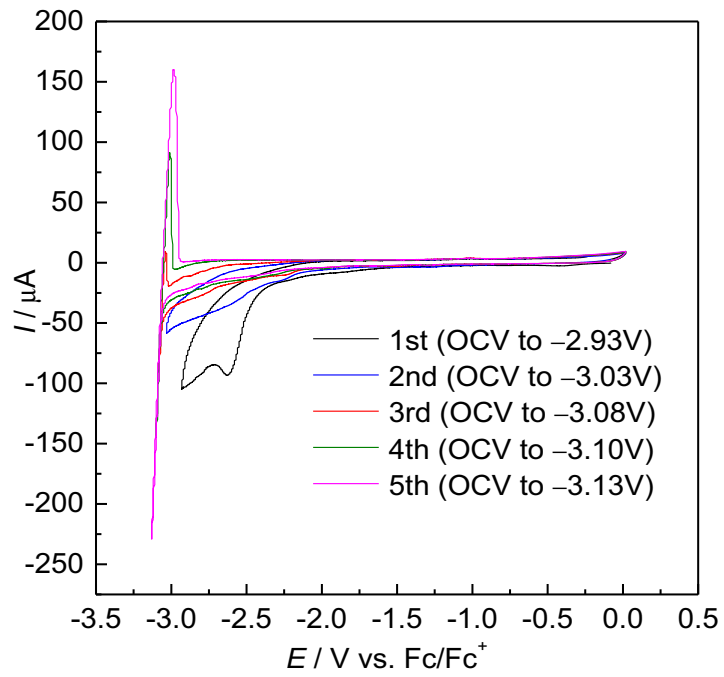

Figure 1. Cyclic voltammograms of SNO-15 composite electrode in $0.9 \mathrm{~mol} \mathrm{~kg}{ }^{-1} \mathrm{NaFSA} / \mathrm{EC}+\mathrm{DMC}(1: 1$ by vol. $)$ at a scan rate of $0.1 \mathrm{mV} \mathrm{s}^{-1}$.

\section{Experimental}

Electrochemical measurements were carried out using a threeelectrode cell. A natural graphite composite electrode (SNO-15 or 3 with average particle size of $15 \mu \mathrm{m}$ or $3 \mu \mathrm{m}$, SEC carbon):polyvinyldene difluoride $(\mathrm{PVdF})=9: 1)$ or mesophase pitch derived spherical graphite composite electrode (GOP-12 with average particle size of $12 \mu \mathrm{m}$, JFE chemical): $\mathrm{PVdF}=8: 2$ ) was used as a working electrode. $\mathrm{Ag} / \mathrm{Ag}^{+}$electrode (silver wire immersed into ethylene carbonate (EC)+dimethyl carbonate (DMC)(1:1 by vol.) (Kishida Chemical Co., Ltd.) mixture containing $0.2 \mathrm{~mol} \mathrm{~kg}^{-1}$ sodium bis(fluorosulfonyl)amide (NaFSA, Nippon Shokubai Co., Ltd.) and $0.04 \mathrm{~mol} \mathrm{~kg}^{-1}$ silver trifluoromethanesulfonate (Sigma Aldrich)) was used as a reference electrode and SNO-15 composite electrode was used as a counter electrode. Electrolyte solutions were EC+DMC $(1: 1$ by vol.) mixture containing $0.9 \mathrm{~mol} \mathrm{~kg}^{-1} \mathrm{NaFSA}$ with and without 5 wt\% fluoroethylene carbonate (FEC) (Tomiyama Pure Chemical Industries). The potential of silver reference electrode was proofread by measuring the redox potential of ferrocene in $\mathrm{EC}+\mathrm{DMC}(1: 1$ by vol.) mixture containing $0.9 \mathrm{~mol} \mathrm{~kg}^{-1} \mathrm{NaFSA}$ and $3 \mathrm{mmol} \mathrm{kg}{ }^{-1}$ ferrocene (Alfa Aesar). Hereafter, all potentials are referred to as vs. $\mathrm{Fc} / \mathrm{Fc}^{+}$. Cyclic voltammetry was conducted between open circuit potential (OCV) and various potentials, and the scan rate was set at $0.1 \mathrm{mV} \mathrm{s}^{-1}$. Charge-discharge measurements were conducted between OCV and $-3.03 \mathrm{~V}$ or $-3.07 \mathrm{~V}$ at various currents. Raman spectroscopy and Xray diffraction (XRD) measurement were used for characterization of the sodium ion intercalated graphitic materials held at various potentials. To prevent the resulting products from decomposition, the samples were kept in a cell filled with Ar. The PITT was performed with a potential step of $10 \mathrm{mV}$ from $-3.02 \mathrm{~V}$ to $-3.03 \mathrm{~V}$. The cells were assembled in an Ar-filled glove box. All electrochemical measurements were carried out using HSV-100 (HOKUTO-DENKO), HJ1001SD8 (HOKUTO-DENKO) and Solartron1470E+1255 (Solartron Analytical).

\section{Results and Discussion}

Electrochemical behaviors of natural graphite.-Figure 1 shows the cyclic voltammograms (CV) of SNO-15 composite electrode in $0.9 \mathrm{~mol} \mathrm{~kg}^{-1} \mathrm{NaFSA} / \mathrm{EC}+\mathrm{DMC}(1: 1)$ at various cut off potentials. At the cycles to $-2.93 \mathrm{~V}$ and $-3.03 \mathrm{~V}$, only reduction currents were observed. These reduction currents were mainly due to the electrolyte decomposition. At the cycles to below $-3.08 \mathrm{~V}$, redox peaks were observed and most likely be due to the deposition and dissolution of sodium metal. Hence, any redox peaks of sodium-ion intercalation

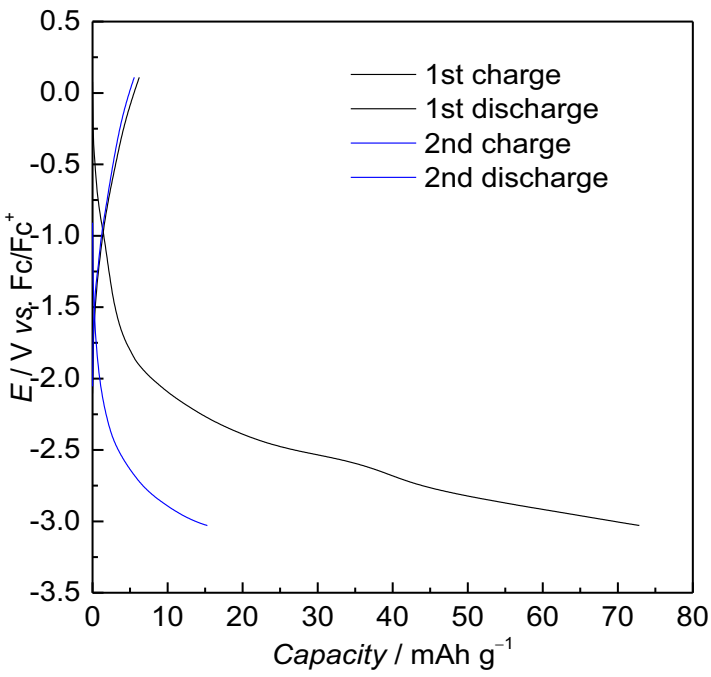

Figure 2. Charge discharge curves of SNO-15 composite electrode in $0.9 \mathrm{~mol} \mathrm{~kg}{ }^{-1} \mathrm{NaFSA} / \mathrm{EC}+\mathrm{DMC}\left(1: 1\right.$ by vol.). Current: $28 \mathrm{~mA} \mathrm{~g}^{-1}$.

were not observed clearly. From the results of CVs, the cut off voltage of charging was decided to be $-3.03 \mathrm{~V}$ to avoid sodium metal deposition. Figure 2 shows the charge-discharge curves of SNO-15 composite electrode in $0.9 \mathrm{~mol} \mathrm{~kg} \mathrm{~kg}^{-1} \mathrm{NaFSA} / \mathrm{EC}+\mathrm{DMC}(1: 1)$. At the 1 st cycle, the large irreversible capacity due to the electrolyte decomposition was observed. The reversible capacity was quite small like $5 \mathrm{~mA} \mathrm{~h} \mathrm{~g}^{-1}$. However, after the reduction process, the OCV did not go back to around $-0.5 \mathrm{~V}$ and showed around $-2.0 \mathrm{~V}$, suggesting a small amount of sodium-ion intercalation into SNO-15.

Structural characterization of natural graphite.-To clarify the structures of SNO-15 after electrochemical reduction, Raman spectroscopy and XRD measurement were performed for SNO-15 composite electrodes held at $-3.03 \mathrm{~V}$ during from 1 day to over 7 days. Figure 3 shows the XRD patterns of SNO-15 composite electrodes pristine and held at $-3.03 \mathrm{~V}$ during over 7 days. Peaks due to the $\mathrm{Cu}$ substrate are denoted as ' $\mathrm{Cu}$ '. Even by over 7 days potential holding, in the XRD patterns for the graphite electrode held at $-3.03 \mathrm{~V}$, there is no peak position shift due to the Na-GIC. However, the peak intensity was decreased compared with that for pristine SNO-15. Based on the above results, it is indicated that although clear sodium-ion

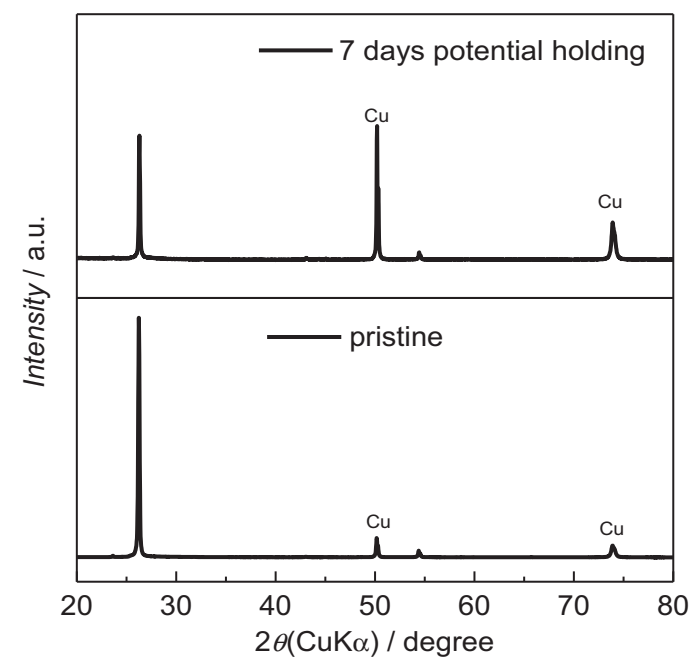

Figure 3. XRD patterns of SNO-15 composite electrodes pristine and held at $-3.03 \mathrm{~V}$ during 7 days. 


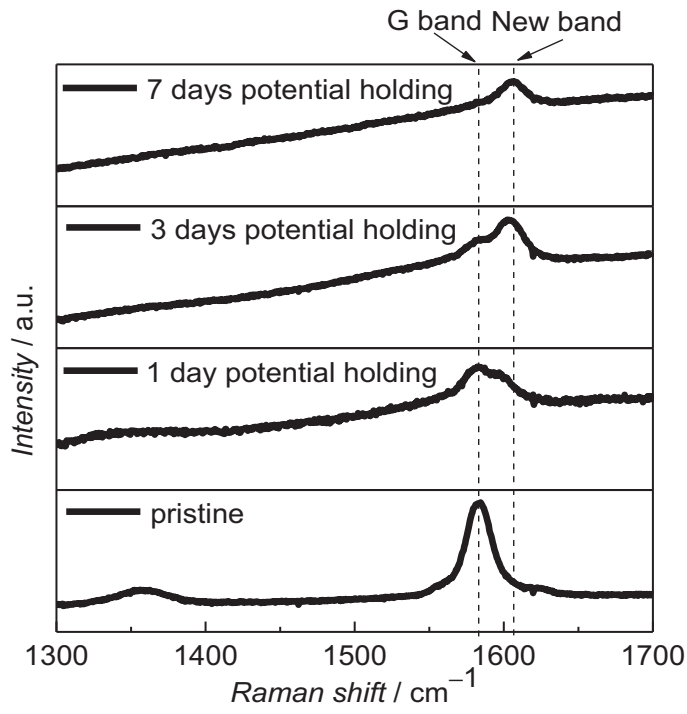

Figure 4. Raman spectra under Ar atmosphere of SNO-15 composite electrodes pristine and held at $-3.03 \mathrm{~V}$ during from 1 day to 7 days.

intercalation didn't occur, the destructive reaction of graphite related with sodium-ion intercalation might proceed. Figure 4 shows the Raman spectra of SNO-15 composite electrodes pristine and held at $-3.03 \mathrm{~V}$ during from 1 day to over 7 days. In the Raman spectra of pristine SNO-15 electrode, only the G-band at $1580 \mathrm{~cm}^{-1}$ was observed. In contrast, a new peak appeared at around $1600 \mathrm{~cm}^{-1}$ for the SNO-15 electrode held at $-3.03 \mathrm{~V}$. The intensity of $\mathrm{G}$ band decreased and that of the new peak increased with increasing holding time. The new band was mainly observed after 7 days. The Raman spectrum didn't change by potential holding over 7 days. At the Raman spectra for Na-GICs, the new peak due to bounding layers that were adjacent with sodium ion appeared at around $1600 \mathrm{~cm}^{-1} .8$ The intensity ratio of G-band and the new peak indicated the formation of a stage $5 \mathrm{Na}-$ GIC after 1 day, a stage 3 Na-GIC after 3 days. After over 7 days, the Raman spectrum was similar to that of a stage 2 GIC, ${ }^{17}$ suggesting the surface of graphite electrode might be the mixture of stage $2 \mathrm{Na}-\mathrm{GICs}$ and small amounts of stage 3 Na-GICs. The intensity of the new peak decreased and that of G-band increased with increasing contact time with air and the new peak disappeared finally, suggesting the decomposition of Na-GICs due to the reaction with air like other alkali-metal GICs. Raman spectroscopy is sensitive to surface of samples and Raman spectra indicated that the formation of Na-GIC was limited on the surface. To the best of our knowledge, this result is the first finding of the electrochemical formation of low stage Na-GICs even only near the surface of graphite above the sodium metal deposition potential. These results suggested that the sodium-ion diffusion distance is very short, and the sodium-ion diffusion inside graphite is slow. In support of the short diffusion distance of sodium-ion, graphite with smaller particle sizes was used to increase capacities of sodium-ion intercalation into graphite.

The charge-discharge capacities of SNO-15 and SNO-3 were compared. Figure 5 shows the charge-discharge curves of SNO-15 and SNO-3 composite electrodes in $0.9 \mathrm{~mol} \mathrm{~kg}^{-1} \mathrm{NaFSA} / \mathrm{EC}+\mathrm{DMC}$ $(1: 1)$ at 28 and $1.8 \mathrm{~mA} \mathrm{~g}^{-1}$. Reversible capacities were larger in small currents than in large currents for both natural graphite composite electrodes. Moreover, reversible capacities of SNO-15 composite electrodes more rapidly decreased than those of SNO-3 composite electrodes at large currents. The potential of SNO-15 electrodes after charging was higher than that of SNO-3 electrodes, suggesting that the utilization ratio of SNO-3 electrodes was larger than that of SNO15 electrodes. Therefore, the reversible capacities can be increased by using small graphite particles, indicating the diffusion distance of sodium-ion is very small.
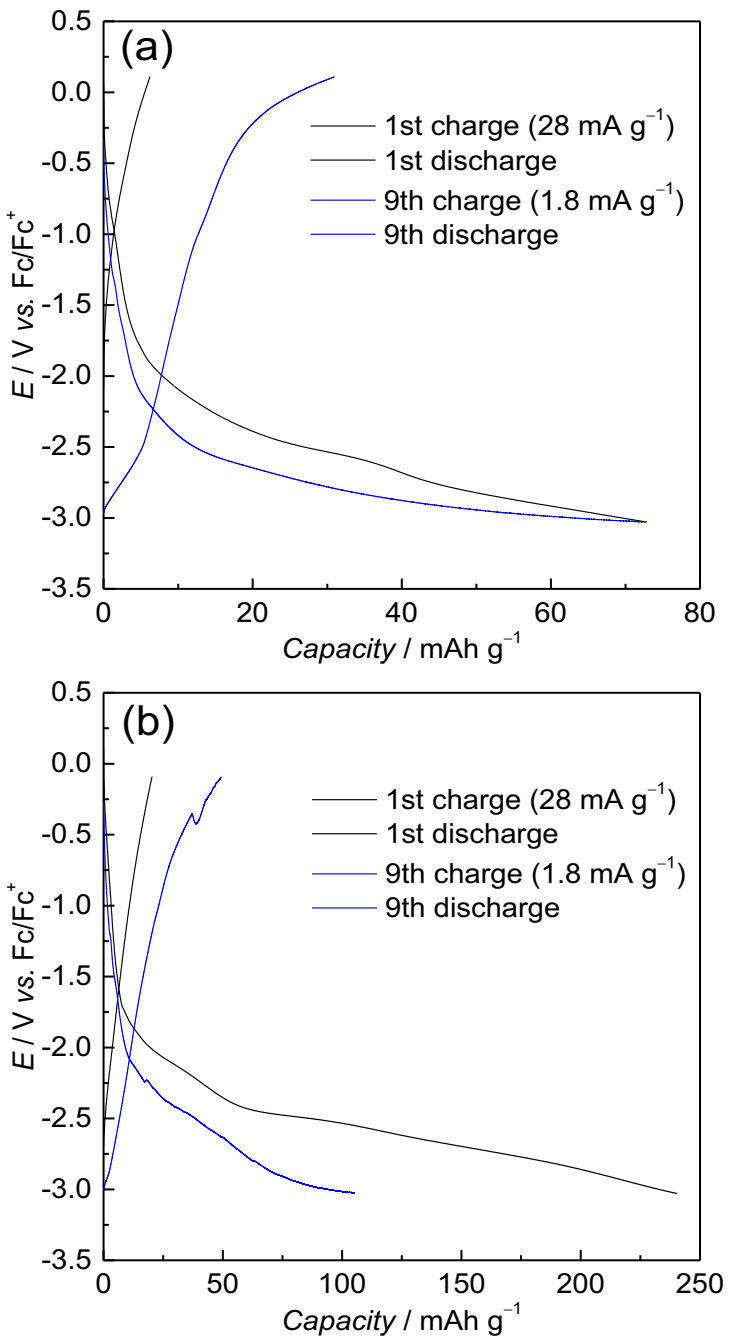

Figure 5. Charge discharge curves of (a) SNO-15 and (b) SNO-3 composite electrode in $0.9 \mathrm{~mol} \mathrm{~kg}{ }^{-1} \mathrm{NaFSA} / \mathrm{EC}+\mathrm{DMC}(1: 1$ by vol.). Current: $28-1.8 \mathrm{~mA} \mathrm{~g}^{-1}$.

Based on the above results and Nobuhara's work, ${ }^{12}$ at the low potential near sodium metal deposition, the lower stage Na-GIC may be formed in bulk by the electrochemical method. Next, we investigated the structure of graphite held at potential of sodium metal deposition. Figure 6 shows the XRD patterns of SNO-15 composite electrodes pristine and held at $-3.07 \mathrm{~V}$ during 3 days. In the XRD patterns of graphite held at $-3.07 \mathrm{~V}$, new peaks at 29.56 and 52.32 (in $2 \theta$ ) identified as sodium metal ${ }^{18}$ were observed and other new peaks at 25.5, 28.88 and 55.98 were observed. As for the latter, the number on these peaks denote $00 \mathrm{l}$ lines. From the $00 \mathrm{l}$ lines in Fig. 5, $\mathrm{c}$ axis repeat distance of $2.46 \pm 0.2 \mathrm{~nm}$ was observed. This value is almost identical to the sum of $0.46 \mathrm{~nm}+0.335 \mathrm{~nm} \times 6=2.47 \mathrm{~nm}$. Hence, the resultant sample can be identified as a stage 7 Na-GIC. ${ }^{7}$ Measuring Raman spectra of graphite held at $-3.07 \mathrm{~V}$ was difficult because of existence of sodium metal and some deposits. Based on the previous report, ${ }^{8}$ high stage Na-GICs seemed to be formed even on the surface of graphite held at $-3.07 \mathrm{~V}$. Sodium ion can intercalate into the bulk of graphite can proceed only at lower potential than sodium metal deposition potential. However, the low stage Na-GICs didn't form into the bulk of graphite even at these potential. The one possible reason for these phenomena is the slow diffusion of sodium-ion. Then, the apparent diffusion coefficient of sodium-ion inside graphite was investigated. 


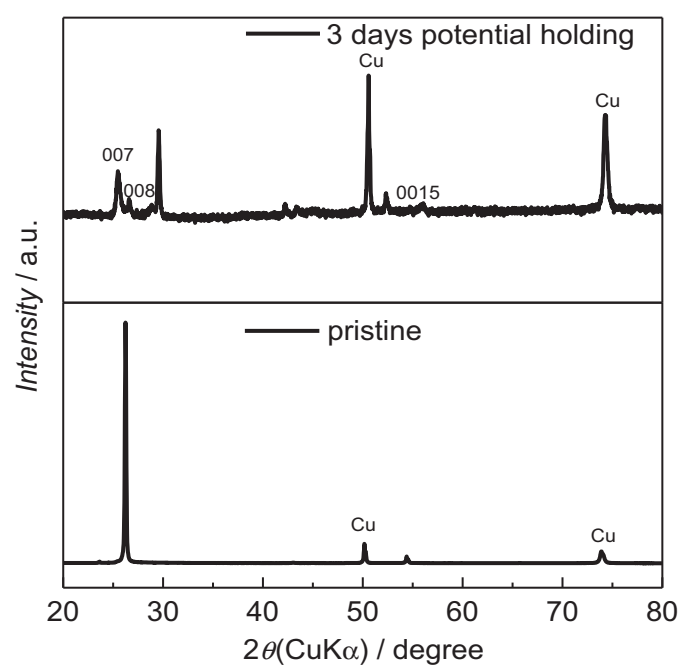

Figure 6. XRD patterns of SNO-15 composite electrodes pristine and held at $-3.07 \mathrm{~V}$ during 3 days.

Apparent diffusion coefficient of sodium-ion inside graphite.Sodium-ion diffuses into the center of spherical graphite particles during sodium-ion intercalation and this diffusion can be expressed by Cottrell equation ${ }^{19}$ like Equation 1 .

$$
I=-n F A C o\left(\frac{D o}{\pi t}\right)^{\frac{1}{2}}
$$

$I$ is current, $n$ is electron transfer number, $F$ is Faladay constant, $A$ is area of electrode, $C_{o}$ is concentration of ion, $D_{o}$ is diffusion coefficient and $t$ is time. Na-GICs might form like shell structure during potential holding. In this study, the diffusion distance of sodium-ion was calculated from charge capacities in chronopotentiograms of NaGICs formed on the surface of the GOP-12 negative electrode held at $-3.03 \mathrm{~V}$ during 3 days in $0.9 \mathrm{~mol} \mathrm{~kg}^{-1} \mathrm{NaFSA} / \mathrm{EC}+\mathrm{DMC}(1: 1)$ with 5 wt $\%$ FEC. FEC was added to the electrolytes to prevent degradation of GOP-12 electrodes by FEC derived surface film on graphite. Figure 7 shows Raman spectra and XRD patterns of the GOP-12 composite electrodes. Raman spectra and XRD patterns indicated the formation of stage $2 \mathrm{Na}$-GICs only at the surface regions of GOP-12 electrodes. Hence, the hypothetical capacities of GOP-12 electrodes into which sodium-ion intercalates into the bulk of GOP-12 was assumed to be $139.5 \mathrm{~mA} \mathrm{~h} \mathrm{~g}^{-1}\left(\mathrm{NaC}_{16}\right)$. Next, the potential step from $-3.02 \mathrm{~V}$ to
$-3.03 \mathrm{~V}$ was performed. As reported by Aurbach et al., ${ }^{16}$ the functional dependence of $I t^{1 / 2}$ on $\log t$ shows different kinetic regions of the intercalation process. In order to calculate the diffusion coefficient, the constant value of the region reflecting the Cottrell behavior was used. The following equation based on the theoretical treatment of the PITT $^{20}$ can be applied to the Cottrell region.

$$
I t^{1 / 2}=\frac{D o^{1 / 2} \Delta Q}{l \pi^{1 / 2}}
$$

$D_{o}$ is the diffusion coefficient of the intercalation species inside graphite, $\Delta Q$ is the amount of charge injected into the electrode and $l$ is a characteristic diffusion distance. Figure 8 shows $I t^{1 / 2}$ on $\log t$ plots and chronopotentiogram during and after potential step. GOP-12 held at $-3.03 \mathrm{~V}$ during 3 days were from 10 to $20 \mathrm{~mA} \mathrm{~h}$ $\mathrm{g}^{-1}$ in the chronopotentiogram. Since GOP-12 is the mesophase pitch derived spherical graphite and sodium-ion can intercalate uniformly from the surface to the center due to the radial orientation of edge planes, it can be assumed that the formation of Na-GIC stopped and $\mathrm{Na}$-GIC made the shell structure in GOP-12 particle. Based on the capacity obtained from chronopotentiogram and the hypothetical capacity of GOP-12, the apparent diffusion distances of sodium-ion were calculated $(l=150 \sim 300 \mathrm{~nm})$. From $I t^{1 / 2}$ on $\log t$ plots, the apparent diffusion coefficients of sodium-ion inside graphite were decided $\left(D_{o}=10^{-13} \sim 10^{-14} \mathrm{~cm}^{2} \mathrm{~s}^{-1}\right)$. The apparent diffusion coefficients of lithium-ion inside graphite calculated by PITT were reported by Aurbach et al. $\left(D_{o}=10^{-8} \sim 10^{-10} \mathrm{~cm}^{2} \mathrm{~s}^{-1}\right) .{ }^{16}$ Hence, the diffusion coefficient of sodium-ion was relatively slower than that of lithium ion inside graphite. However, the values of the diffusion coefficients might not be the main reason for the limited reactivity of sodiumion. For example, lithium-ion some positive electrode materials of $\mathrm{LiMn}_{2} \mathrm{O}_{4}$ and $\mathrm{LiMnPO}_{4}$ and also sodium-ion in hard carbon showed similar diffusion coefficients. ${ }^{21-23}$ Therefore, the limited reactivity of electrochemical sodium-ion intercalation into graphite might be derived from not the kinetic properties but the thermodynamic properties like the difference of intercalation potential between the surface and the bulk of graphite. The further investigation about the thermodynamic properties of sodium-ion intercalation is necessary to reveal the reactivity between sodium-ion and graphite.

\section{Conclusions}

Structural changes of graphite during electrochemical sodium-ion intercalation were investigated. A new peak assigned to Na-GIC was not observed in XRD patterns, but a new band due to the formation of Na-GIC was observed in the Raman spectra after potential holding of natural graphite composite electrodes at $-3.03 \mathrm{~V}$. The intensity
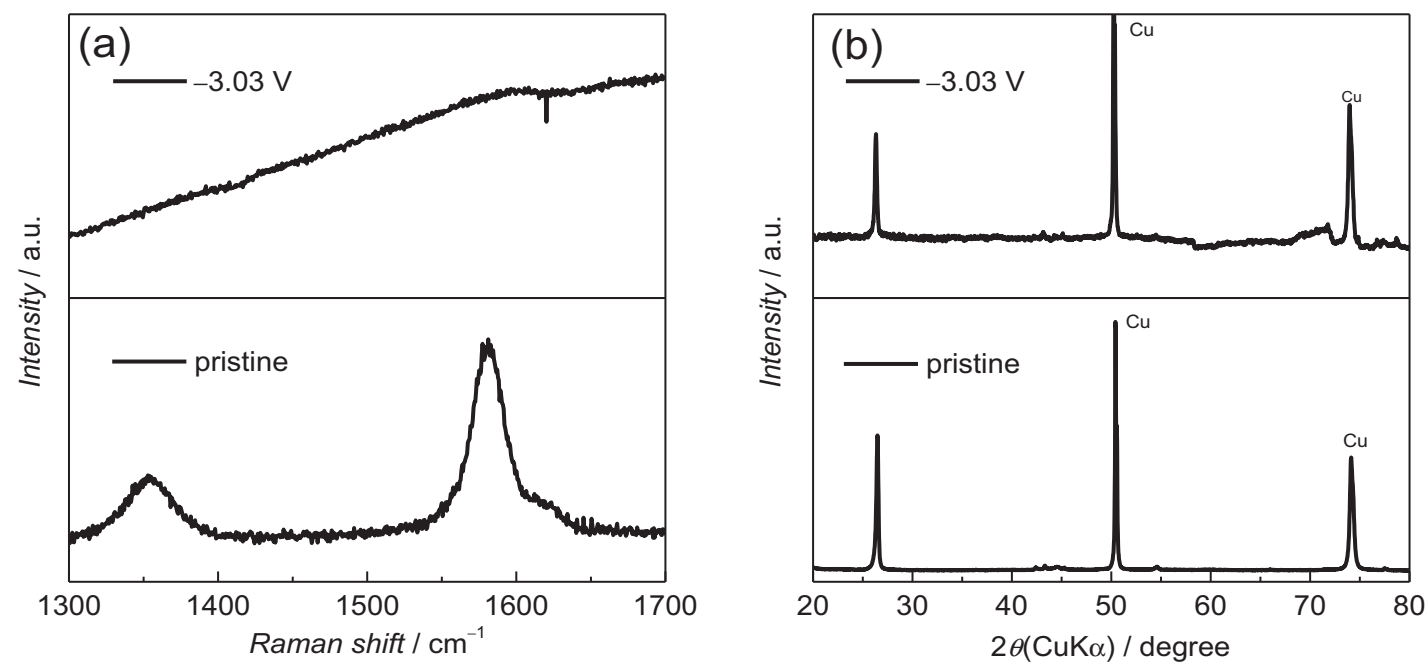

Figure 7. (a) Raman spectra and (b) XRD patterns under Ar atmosphere of GDP-12 composite electrodes pristine and held at $-3.03 \mathrm{~V}$ during 3 days. 

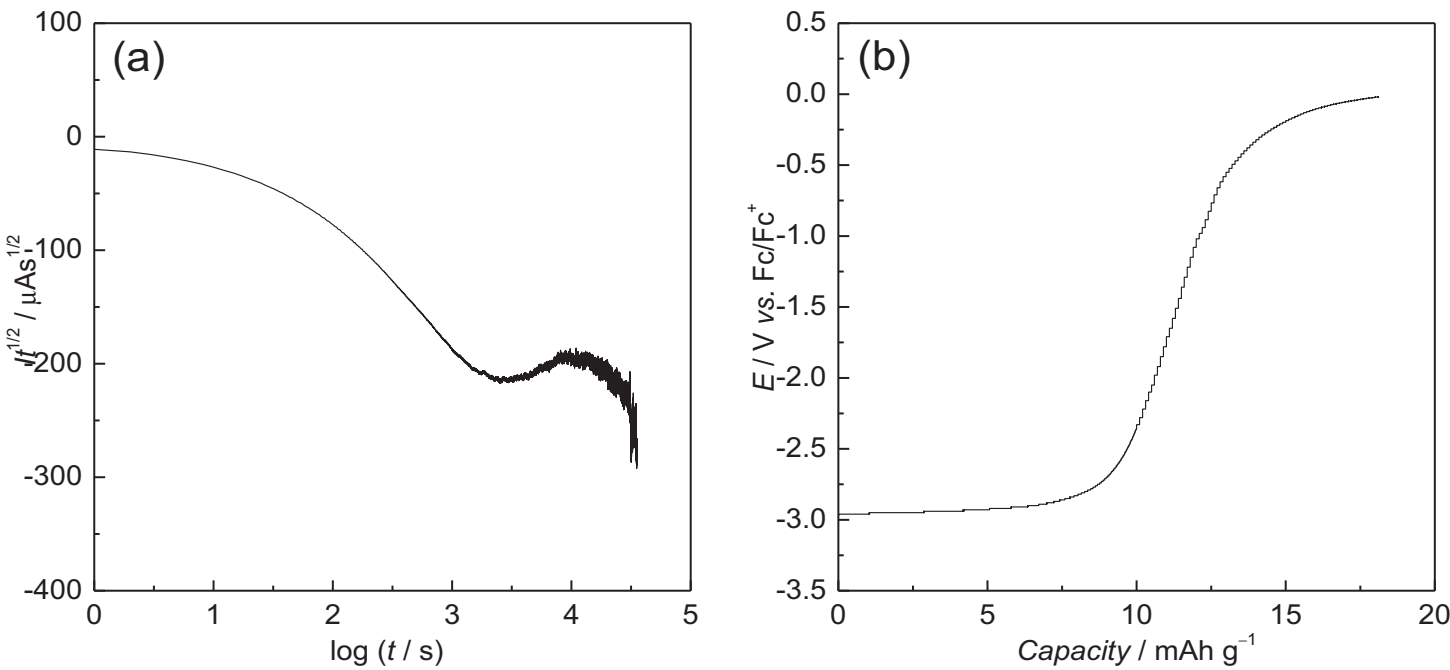

Figure 8. (a) $I t^{1 / 2}$ vs. $\log t$ plot calculated from chronoamperometric curve during potential step and (b) Chronopotentiogram after potential step at $0.9 \mathrm{~mA}^{-1}$ of GOP-12 composite electrode. The potential step was $10 \mathrm{mV}$ from $-3.02 \mathrm{~V}$ to $-3.03 \mathrm{~V}$ vs. $\mathrm{Fc} / \mathrm{Fc}^{+}$.

of these new bands increased as potential holding time increased. The mixture of stage $2 \mathrm{Na}$-GICs and small amounts of stage $3 \mathrm{Na}$ GICs seemed to be formed electrochemically only near the surface of graphite by 7 days potential holding at $-3.03 \mathrm{~V}$. In the case of holding potential of $-3.07 \mathrm{~V}$, although sodium-ion intercalation proceeded into the bulk of graphite, the low stage Na-GICs didn't form in the bulk, suggesting that sodium-ion diffusion distance is very short, and sodium-ion diffusion inside graphite is slow. In addition, the reversible capacity of small size graphite was larger than that of large size graphite. To investigate the kinetic properties of sodiumion inside graphite, the apparent diffusion distance and coefficient of sodium-ion inside mesophase pitch derived spherical graphite were measured by chronopotentiometry and PITT. As a result, the calculated sodium-ion diffusion distance was actually very short like 150-300 nm. However, the apparent diffusion coefficient of sodiumion was not so small as the origin of the limited reactivity between sodium-ion and graphite. Hence, the reactivity between sodium-ion and graphite should be explained based on not the kinetics but the thermodynamics.

\section{Acknowledgment}

This work was partially supported by ESICB, Kyoto University.

\section{ORCID}

Tomokazu Fukutsuka (D) https://orcid.org/0000-0002-8731-9078

Kohei Miyazaki (D) https://orcid.org/0000-0001-5177-3570

Takeshi Abe (D) https://orcid.org/0000-0002-1515-8340

\section{References}

1. N. Yabuuchi, K. Kubota, M. Dahbi, and S. Komaba, Chem. Rev., 114, 11636 (2014).

2. S. Komaba, W. Murata, T. Ishikawa, N. Yabuuchi, T. Ozeki, T. Nakayama, A. Ogata, K. Gotoh, and K. Fujiwara, Adv. Funct. Mater, 21, 3859 (2011).

3. H. Hou, X. Qiu, W. Wei, Y. Zhang, and X. Ji, Adv. Energy Mater, 7, 1602898 (2017).

4. X. Xiang, K. Zhang, and J. Chen, Adv. Mater., 27, 5343 (2015).

5. M. S. Dresselhaus and G. Dresselhaus, Adv. Phys., 30, 139 (1981).

6. R. C. Asher and S. A. Wilson, Nature, 181, 409 (1958).

7. A. Metrot, D. Guerard, D. Billaud, and A. Herold, Synth. Met., 1, 363 (1979/80).

8. N. Akuzawa, J Yoshioka, C. Ozaki, M. Tokuda, K. Ohkura, and Y. Soneda, Mol. Cryst. Liq. Cryst, 388, 415 (2002).

9. I. A. Udod, H. B. Orman, and V. K. Genchel, Carbon, 32, 101 (1994).

10. N. Adhoum, J. Bouteillon, D. Dumas, and J. C. Poignet, Electrochim. Acta, 51, 5402 (2006).

11. N. Akuzawa, T. Komoda, K. Tamada, T. Hirayama, and H. Imagawa, TANSO, 249 191 (2011).

12. K. Nobuhara, H. Nakayama, M. Nose, S. Nakanishi, and H. Iba, J. Power Sources, $\mathbf{2 4 3}, 585$ (2013).

13. A. Zolochevsky, J. G. Hop, G. Servant, T. Foosnaes, and H. A. Oye, Carbon, 41, 497 (2003).

14. M. M. Doeff, Y. Ma, S. J. Visco, and L. C. De Jonghe, J. Electrochem. Soc., 140, L169 (1993).

15. R. Alcantara, J. M. Jimenez Mateos, and J. L. Tirado, J. Electrochem. Soc., 149, A201 (2002).

16. M. D. Levi, E. A. Levi, and D. Aurbach, J. Electroanal. Chem., 421, 89 (1997).

17. M. Inaba, H. Yoshida, Z. Ogumi, T. Abe, Y. Mizutani, and M. Asano, J. Electrochem. Soc., 142, 20 (1995).

18. C. S. Barrett, Acta. Cryst., 9, 671 (1956)

19. A. J. Bard and L. R. Faukner, Electrochemical. Methods, Wiley: New York (1980)

20. C. J. Wen, B. A. Boukamp, R. A. Huggins, and W. Weppner, J. Electrochem. Soc., 126, 2258 (1979).

21. E. Deiss, Electrochim. Acta, 47, 4027 (2002).

22. H. Manjunatha, K. C. Mahesh, G. S. Suresh, and T. V. Venkatesha, Electrochim. Acta, 80, 269 (2012).

23. L. Xiao, Y. Cao, W. A. Henderson, M. L. Sushko, Y. Shao, J. Xiao, W. Wang, M. H. Engelhard, Z. Nie, and J. Liu, Nano Energy, 19, 279 (2016). 